\title{
Intervention Of Transformational Collegial Leadership To Develop Human Resources
}

\author{
Prakash Singh, Nelson Mandela Metropolitan University, South Africa
}

\begin{abstract}
Transformational collegial leadership (TCL) is a collective action generated by transforming leadership which empowers all individuals who participate in this process, whether it is in business or education, or in any other organization. TCL is a leadership style that facilitates the redefinition of a people's mission and vision, a renewal of their commitment, and the restructuring of their systems for goal accomplishment. Recent research is strongly supportive of collegiality as a key factor in transforming traditional bureaucratic management practices in organizations. Farreaching organizational and structural changes are required to address the severe imbalances in the provision and strong bureaucratic controls in many organizations at all levels. Transformation involves every aspect of life, and education is no exception. Hence, this qualitative study investigated the impact of TCL on developing human resources in two primary schools which were purposively selected to participate in this study. Primary school leaders, from a transformational perspective, view employees as potential leaders, with the focus being to enable leaders to act through fostering collaboration and strengthening employees. This involves competencies such as the effective use of power, developing human resources and the ability to cope, and initiating change from both the leader and the employee. The collegial leader then becomes a catalyst for growth, through attention to structures, development opportunities for employees and in the expectations and the manner in which interaction with employees takes place. This study affirms that human resource development and TCL embrace the values of collaboration, confrontation, authenticity, trust, support and openness.
\end{abstract}

Keywords: Transformational Collegial Leadership; Transforming Traditional Bureaucratic Management Practices; Developing Human Resources; Shared Vision

\section{INTRODUCTION}

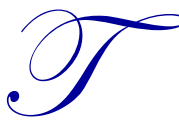

ransformational collegial leadership (TCL) is a collective action generated by transforming leadership which empowers all those individuals who participate in this process, whether it is in business or education, or in any other organization. Telford (1996) refers to transformational leadership as members of an organization, pursuing shared beliefs through combined efforts. In essence, TCL is a leadership style that facilitates the redefinition of a person's mission and vision, a renewal of their commitment, and the restructuring of their systems for goal accomplishment (Leithwood, 1992). The collegial leader should promote the articulation and sharing of a vision as well as fostering group goals (Leonard \& Leonard, 1999). Although transformational leadership requires leaders and followers to unite in the attainment of common goals (Sergiovanni, Burlingame, Coombe \& Thurston, 1992), this partnership does not always take place as planned, on level playing fields where the unequal distribution of power, time, resources and knowledge, which favour the leader, remain unchanged (Duigan, 1990). Transformation involves every aspect of life, and education is no exception.

Far-reaching organizational and structural changes are required to address the severe imbalances in the provision and strong bureaucratic controls over education at all levels (National Department of Education, 1998). At no time in our existence is change more imminent and the future more challenging than in our schools. Elliott-Kemp and Elliot-Kemp (1992) believe that one has to guard against the implementation of too many changes that could cause shattering stress and disorientation and consequent loss of effectiveness in organizations. Walker and Vogt (as quoted by Rossouw, 1996) warn against initiating change for the sake of change without being knowledgeable about its impact in theory and practice, saying it can be as counterproductive as doing nothing. 
Research (Singh, 2013a; 2013b; 2013c; 2013d) conducted thus far is strongly supportive of collegiality as a key factor in transforming traditional bureaucratic management practices in organizations. Dantley (2005) points out that much of the thinking in the field of leadership has been shaped by the ideas and tenets of what is generally referred to as scientific management, and Frederick W. Taylor is considered to be the father of this influential management theory. Scientific management explores the quickest methods to accomplish a task, with the least number of body motions necessary to do a job efficiently. Researchers such as Kotter (2011) confirm that managers "organize" to create human systems that can implement plans as precisely and efficiently as possible. The role of the manager, then, is to discover the most time- and cost-efficient way to accomplish tasks, and training is usually provided so that employees can reproduce the process, the results of which can always be predicted and quantified. Kotter (2011) makes a clear distinction between management and leadership and, in doing so, aptly supports the existence of both in organizations:

Leadership is different from management, but not for the reasons most people think. Leadership isn't mystical and mysterious. It has nothing to do with having "charisma" or other exotic personality traits. It is not the province of a chosen few. Nor is leadership necessarily better than management or a replacement for it. Rather, leadership and management are two distinctive and complementary systems of action. Each has its own function and characteristic activities. Both are necessary for success in an increasing complex and volatile business environment. (p. 37)

A leader focuses on people and inspires trust whereas a manager focuses on systems and structures and depends largely on control measures to get the job done (Bennis, 1994). A leader challenges the status quo which the manager accepts as "the classic good soldier" (Bennis, 1994). The differences between the manager and the leader, as described by Bennis, clearly distinguish the artist (leader) from the technocrat (manager). Evidently, the competencies associated with emotional intelligence are clearly identifiable in the expected traits of collegial leadership (Singh, 2013b). A traditional manager thinks for his/her staff on what to accomplish in the organization whereas a collegial leader thinks with them. It is not uncommon to find that a traditional manager does the planning for his/her employees. This is in sharp contrast to a collegial leader who would welcome joint planning with his/her employees. Apparently, a manager normally gets things done through the efforts of other people, while a leader gets things done by working collaboratively with other people. A traditional manager tends to be a technocrat and wears only one hat - the hat of the boss. On the other hand, a collegial leader is, to a large extent, a humanist and consequently wears many hats. A traditional manager is therefore one-dimensional in managing his/her subordinates; a collegial leader is considered to be multidimensional in leading his/ her peers. Usually, a traditional bureaucratic manager tends to adopt an autocratic approach to decision-making whereas a collegial leader would usually embrace a collaborative approach to decision-making. Hence, a traditional manager is driven by the objectives of his/her organization whereas a collegial leader is inspired by the shared vision of his/her organization (Kochan \& Reed, 2005; Singh, 2005; Thilo, 2004; Kouzes \& Posner, 1997; Singh, 2013c).

It must be acknowledged that TCL and management are both essential for the success of any organization. However, in this paper, the limitations of traditional bureaucratic measures that are aligned to traditional bureaucratic management practices (TBMPs) are critically discussed to evoke the significance of TCL strategies for organizations to cope with current changes and challenges that they are constantly faced with. As pointed out by Kotter (2011), most US corporations, similar to many others in the world, today are over-managed and underled which means that they need to develop their capacity to exercise leadership. He emphasizes that successful organizations don't wait for leaders to come along; they actively seek out people with leadership potential as part of the organizational imperative and expose them to career experiences designed to develop that potential. With careful selection, mentoring (Singh, 2013c), and encouragement, dozens of employees can assume significant leadership roles in organizations, which includes both business and educational organizations such as schools. West-Burnham, Bush, O'Neill and Glover (1995) believe that the three concepts - leadership, management and administration - also have an international difference; for what appears to be management to the British reader is considered to be administration to the American reader, and leadership for the latter would then drive both management and administration. The issue is one of comparative custom and practice. West-Burnham et al. (1995) further propose a three-way dichotomy between leadership (concerned with values, vision and mission), management (concerned with the execution, planning, organizing and deploying) and administration (primarily concerned with the operational details of the organization). 
The complexity of the schools' structures is described by King and Van der Berg (1991) as being a dynamic interrelationship between the social backgrounds of learners and their expectations of school. This can also take place between teacher belief systems and styles, between examinations and curriculum delivery, between formal school structures and hidden agendas, and all other elements that are both cause and effect of one another. Carlson (1995) further enforces this point by noting the current moves in education away from Taylor's scientific management movement that emphasized the bureaucratic model of management in which education was seen as a public service, to a more market-driven type of education. In a market-driven education, there are so many interrelations, including new demands from customers of education - learners, parents, employers, community groups and higher education institutions - and also peer demands from the providers of education - teachers, teacher unions, teacher trainers and industry. It is these expressed concerns in the leadership of schools that bring one to question how far leadership in schools has moved away from the traditional bureaucratic models of management to the more TCL style characterized by collaboration amongst all employees with participatory decision-making.

An ideal learning community is organized in a way that fosters an open flow of thoughts; stimulates critical reflection about analyses of ideas, policies, problems, and solutions; creates notions of what is universally acceptable as being the common good and develops a concern for the rights and dignity of all people (Kochan \& Reed, 2005). It is expected that in such a setting, staff, learners, parents and other stakeholders would function together using democratic principles to improve the organization and enhance the quality of instruction and learning. Participatory teaching, learning and assessment would contribute to an improved school environment and would enable educational leaders to balance "bottom-up processes" with "top-down regulations" (Veugelers \& Zijlstra, 2002). Successful school leaders are recognized as those who, in order to ensure that their schools provide relevant learning opportunities, engage in reflective practices to maintain staff satisfaction and emotional intelligence (Day, 2000). They are able to mediate successfully between internal harmony and external needs because, as Day (2000) points out, they need to nurture their critical thinking and emotional intelligence through reflection by testing what they know against what is happening both inside and outside the school.

All stakeholders, especially teachers, stand to gain substantially from transformational leadership, as issues can be addressed and alternatives sought through an increased knowledge base, greater understanding of decisions and improved understanding of reasons and methods for change (Singh, 2010; Chapman, 1990). However, extending participation in decision-making to as many stakeholders as possible in schools can raise the possibility that people and relationships can affect the process adversely through incorrect planning, weak motivations, problematic communication networks, behaviour of individuals and structural disorganization (Carl \& Franken, 1996; Singh, 2010). The primary objective of this study was therefore to gauge the extent to which organizations such as schools have affected a shift from TBMPs toward TCL and how this can affect the development of human resources. Many similarities exist between educational and business organizations and hence, the theoretical framework that follows is applicable widely to both organization types. Similarly, the research findings of this study and the recommendations can be applied to developing human resources in many organizations across (private and public) sector boundaries.

\section{TRANSFORMATIVE LEADERSHIP}

Harford (2012) unequivocally states that it is "difficult to be unmoved by conditions in sweatshops" when the human factor becomes secondary to the product (p. 258). In most jobs, there are more than two variables (the latter referring to speed and reliability) at play and in these jobs, leaders, rather than traditional managers, would need a more holistic, all-encompassing measure of job performance and satisfaction (Harford, 2011). Hellriegel, Jackson, Slocum, Staude, Amos, Kloper, Louw and Oosthuizen (2006, p. 6) define a manager as "a person who plans, organizes, directs, and controls the allocation of human, material, financial, and information resources in pursuit of the organization's goals." In terms of their definition, a successful manager capably performs four essential managerial tasks - planning, organizing, leading, and controlling. The task of leading involves communicating with and motivating employees to perform the tasks necessary to achieve the organization's goals within the context of a supporting organizational culture. Hellriegel et al. note that leadership involves influencing employees to act toward the attainment of a goal and this is based on interpersonal relationships, not administrative activities and directives. They strongly believe that employees throughout the organization can and should exercise leadership, and the best organizations have effective leaders at all levels. They further point out that successful 
leadership depends on the leader establishing trust, clarifying the direction in which people should be headed, communicating so that people would feel confident that they could make the right decisions, encouraging others to take risks and, finally, having a source of power which Hellriegel et al. regard as the ability to influence the behaviour of others through the devolution of power. Such traits allude to the expected norms and values of being collegial leaders.

A collegial leader can be classified as an emancipator seeing that s/he contributes extensively to the creation of an environment for emancipation. The emancipation of teachers as decision-makers and leaders refers to the creation of a climate in a school that encourages teachers to participate in the development and change process in the collegial leadership of their school. Emancipation in a collegial climate will mean that teachers who demonstrate power through expertise, are afforded the same opportunities and leadership rights as those placed in positions of hierarchical power (Singh, 2013c). They need to feel comfortable in their capacity as decision-makers and be unafraid to take decisions based on professional work ethics and collegial principles. Emancipation does not mean that teachers are given unconditional freedom, but rather it includes the assumption of responsibility and accountability within an individual's particular field of expertise. With freedom comes responsibility and commitment to the school's shared and chosen direction (Singh, 2005; 2013c). In support of TCL strategies, Barth (2006) asserts that:

A precondition for doing anything to strengthen our practice and improve a school is the existence of a collegial culture in which professionals talk about practice, share their craft knowledge, and observe and root for the success of one another. Without these in place, no meaningful improvement - no staff or curriculum development, no teacher leadership, no student appraisal, no team teaching, no parent involvement, and no sustained change - is possible. (p. 33)

In a TCL environment, policies are determined and decisions are made through a process of discussion leading to consensus (Bush, 1993). There is power sharing based on the expertise and mutual understanding of the school's shared vision. The authority of expertise advocated by a collegial approach encourages teachers to collaborate through shared values and establish decision-making skills based on their expertise. This implies that teachers should mostly be held accountable when they are included in the decision-making process in a meaningful and collegial manner. Kochan and Reed (2005) describe the nature of collaborative (collegial) leadership as follows:

Collaborative leadership incorporates notions of reciprocity and working toward a common end. It is a relational experience that is defined in practice by those involved as they interrelate with one another and the context in which they operate. The ultimate goal of collaborative leadership is to create democratic learning communities in which power is shared and there is mutual belief in working together for the common good. (p. 72)

Members of a collaborative team will need to be able to trust that the principal is supportive of their efforts and their input is regarded as meaningful. If such trust does not exist, there will be little chance of successful collaboration in an environment where sincerity is viewed with suspicion and doubt. Collegiality, therefore, may be described as the way in which teachers and principals share common values, common goals, accountability and a sense of trust built on a foundation of congeniality (Sergiovanni, 1991). When a relationship is an effective collaboration, leaders maximize their ability to get what they want or need from their staff members. After all, as Stein and Book (2001, p. 112) point out, "no one is going to give you what you desire if they feel misunderstood or attacked. By contrast, every time others feel as if you're in tune with them, they feel validated. The emotional bond between you strengthens and the other person is more apt to work with, not against you." According to Gardner and Stough (2002), in order for educators to reach a level of job satisfaction that produces high levels of efficiency and effectiveness, the principal (as a collegial leader) needs to demonstrate very specific emotionally intelligent competencies and leadership skills:

The ability of the leader to be able to identify and understand the emotions of others in the workplace, to be able to manage their own and others' positive and negative emotions, to be able to control emotions in the workplace effectively, to utilise emotional information when problem solving, and to be able to express their feelings to others is integral to the leader being effective at creating appropriate levels of job satisfaction. (p. 76) 
Collegiality should be lauded as a democratic value in education that contributes to the enfranchisement and emotional well-being of all its employees. Kotter (2011) points out that organizations should remember that strong leadership with weak management is no better, and is sometimes actually worse, than the reverse. He suggests that the real challenge is to combine strong leadership and strong management and each to balance the other. Kotter explains the difference between management and leadership as follows:

Management is about coping with complexity; it brings order and predictability to a situation. But that's no longer enough - to succeed, companies must be able to adapt to change. Leadership, then, is about learning how to cope with rapid change. (p. 39)

The above distinction, according to Kotter, plays out as follows:

- $\quad$ Management involves planning and budgeting whereas leadership involves setting direction.

- Management involves organizing and staffing while leadership involves aligning people.

- $\quad$ Management involves control and solves problems. Leadership provides motivation. (p. 39)

Clearly, the distinction is about traditional management practices as opposed to TCL practices. WestBurnham et al. (1995) believe the introduction of change in organizations, as in school improvement, cannot be guaranteed by traditional management strategies, but rather by transformational leadership which ensures the commitment of followers. Control is so central to management that highly motivated or inspired behaviour of employees is almost irrelevant, as is aptly pointed out by Kotter (2011):

Managerial processes must be as close as possible to fail-safe and risk free. That means they cannot be dependent on the unusual or hard to obtain. The whole purpose of systems and structures is to help normal people who behave in normal ways to complete routine jobs successfully, day after day. (p. 49)

Kotter also explains why leadership is different:

Achieving grand visions always requires a burst of energy. Motivation and inspiration energize people, not by pushing them in the right direction as control mechanisms do, but by satisfying basic human needs for achievement, a sense of belonging, recognition, self-esteem, a feeling of control over one's life, and the ability to live up to one's ideals. (p. 49)

The transforming leader, while still responding to the needs among followers, looks for motives to satisfy these needs by enhancing opportunities, empowering people, giving more freedom and the full support of the leader in initiatives. This kind of leader secures substantial commitment of time and energy from teachers, in a drive to change attitudes of students and parents of the school community where previously there were low levels of achievement and commitment (Preedy, 1993). The transformation of leadership is a process through which the leader must actively pass. The transformational leader attempts to achieve a common vision. In doing so, the employees are empowered to such an extent that they are prepared to take chances and to experiment. The transformational leader needs knowledge of current theories, change and experience, as well as the ability to lead. Such a leader changes his beliefs of teachers so that previously dependent teachers can operate inter-dependently in decision-making and accept responsibility for these decisions (Carl \& Franken, 1996). Carl and Franken (1996) further believe that transformational leadership developed collegiality of teachers in the execution of their duties that created a harmonious work environment and had teachers working well as a collegial team emphasizing cooperation based on mutual trust and respect for each other. Transformational teachers display a balance between peopleorientated and task-orientated leadership. They make a concerted effort to build relationships and support their peers, jointly formulate aims and plan strategies. Transformative leadership, therefore, focuses and builds on a shared vision that can be achieved through the empowerment of people. 


\section{RESEARCH DESIGN}

\section{Research Method}

The qualitative research method was used for this study in order to provide rich descriptions and explanations of situational influences. This is a conscious move away from the positivistic, reductionist approach of behaviourism to a more descriptive and naturalistic phenomenology of collegial leaders in action. Marshall and Rossman (in Estler, 1988) view qualitative research as an inquiry that must occur in a natural setting rather than in an artificially constrained one, such as an experiment. The purpose of qualitative research is twofold in that it tries to "find out what is in someone else's mind ... to access perspectives of the person being interviewed, and to form a holistic understanding of the type of leadership currently used in the schools researched" (Scheurick, 1997). The authentic and natural state of the interview allows qualitative researchers to adopt methods which emphasize progressive focusing, whereby the shape of the research is not determined before field work begins, but is responsive to the initial data collected (Scott \& Usher, 1996).

Two urban schools as organizations were identified to take part in the research. The research was limited to two schools as case studies at these organizations provided the researcher with ample opportunities to make an intensive study of TCL strategies by making use of observations and semi-structured interviews. The assumption was that the leadership issues investigated at the two organizations could be identified with similar organizations and that the findings of this study therefore could be related to similar organizations sharing the same organizational culture and climate. The schools were selected by means of purposeful sampling since they offered a diverse mixture of management and leadership styles. Organization $A$ was identified as a school that was in the early stages of TCL. Very clear lines of management in all committees and structures still existed and the affluent school community was still embedded in bureaucratic structures. The school governing body was the most important body in this organization and all major decision-making took place here. Organization $B$ was identified because it fell well within the scope of TCL where all members of a diverse school community worked harmoniously together and where a tradition of collegial decision-making existed. The school's governing body was functioning effectively and the degree of parental support and interest in educational issues was increasing. All employees at this school were involved in the school's committee structures where there was co-operation and collegial support for each other and for continuous professional development.

Ten one-hour interviews were held on-site; five in each school. The principal, deputy principal (DP), head of department (HOD) and two teachers from each school were interviewed. The nature and purpose of the study were described to each school principal before the interviews were conducted. General accounts of causal linkages between the elements of TCL and school success were sought. The interview questions clearly delineated the area of investigation and tied the questions to the nature of the study; namely, the effect of TCL on developing human resources in schools. The way in which the questions were asked differed, not in their content but in terms of their language. This was necessitated by the language style employed by the various interviewees. From the outset, an open discussion was encouraged and although the course of the interview was more or less dictated by the semistructured questions, subjects felt comfortable enough to elicit facets that had not been anticipated. This proved to be most valuable and provided further direction for the study. Each interview was taped, with the interviewee's approval, and immediately afterwards, key points that had emerged were listed; for example, 'shared decisions,' 'relationship of trust,' 'open communication.' Later, these elements were classified and categorized. Data from the two schools was cross-referenced and sifted, classified and reclassified, summarized and refined until the findings were presented accurately and cogently. Ultimately, the purpose of the study was linked to the findings in determining what leaders do in organizations, such as schools and the consequences of their leadership style on developing human resources.

\section{Validity and Reliability}

Critics of the qualitative approach argue that imprecise measurement, weak generalization of findings, vulnerability to bias, overload of data and extreme labour intensiveness make these methods less than desirable (Telford, 1996). However, if reliability of the research is such that it measures what it is expected to measure, then, according to Anderson (1990), it must be deemed to be valid. Meanings emerging from the data must be tested for 
their plausibility, their sturdiness and their validity (Telford, 1996). Scott and Usher (1996) advocate that the naturalistic type of inquiry can be structured to represent reality directly. Scheurich (1997), on the other hand, sees the relationship between explanation and reality to be, at best, uncertain. Naturalistic inquiry is an intensely personal process and the unknowing author can colour, taint or distance both the process itself and eventual research outcome through the intrusion of personal values and attitudes (Telford, 1996).

The view expressed in this study strongly favours the use of TCL in the quest for organizational success. Rather than this subjective view being seen as a stumbling block toward reliability, it can be used as a vantage point in the research process. Scott and Usher (1996) support this view by arguing that although it is impossible to escape one's pre-understanding, it is precisely through the interplay between one's interpretive framework or preunderstandings and the elements of the actions one is trying to understand, that knowledge can be developed. In other words, one's pre-understanding, far from being closed prejudices or biases (as they are thought of in positivist, empiricist epistemology), actually makes one more open-minded because in the process of interpretational understanding, they are put at risk, treated, and modified according to what one is trying to test.

\section{DISCUSSION OF FINDINGS}

\section{Bureaucratic Management Model}

Elements of the bureaucratic model came under close scrutiny. These characteristics (such as authoritative relationships and closed communication) of the bureaucratic model can be related to the traditional type of management in a school that is very rigid and where there are very definite lines of authority from the headmaster, deputy head, heads of departments, teachers, parents and learners. It is a kind of management that is supervisory in nature, where recordkeeping and evaluation of staff play an important role. Aspects of the industrial model, where individual worth is not recognized and task-oriented leadership is emphasized, can also be noted in this bureaucratic management model. However, the overriding feature of leadership behaviour in the participating schools was the commitment and belief in the change process from the bureaucratic model to transformational leadership. Notwithstanding the commitment to change, the schools differed with their emphasis on bureaucratic constraints in their current education situation with Organization A still being influenced by traditional roles of bureaucracy as compared to Organization B which was more progressive to embrace TCL.

\section{Collegial Leadership Model}

An overriding feature of this model is the strong commitment to and belief in participatory processes. Participating schools agreed that shared involvement was more likely to succeed than not and that changes brought about without employee involvement would not receive the same commitment from those concerned. Consultation and representation were the foundation characteristics in each school, reflecting a valuing of others in the school community. In both schools, leaders saw the connection between leadership opportunity and professional development, where leadership density leads to professional development in a wide range of staff. It was clear from the responses that both schools viewed participation as important and that structures were in place which support and develop this kind of transformative collegial culture. The following characteristics of the collegial model, which also form an integral part of TCL, were present in the participating schools:

- $\quad$ Open-door policy which invites all people to show expression by participating in a participatory democratic process.

- Opportunities for all to take an active part in the formal processes and commitment, belief and trust in the democratic process.

- $\quad$ Respect and valuing of all and a secure and relaxed atmosphere to assume responsibility not purely linked to seniority and encouragement of others to take on responsibilities.

The collegial model emphasizes the valuing of individuals where there is a breadth of leadership and an absence of hierarchy and a belief in the democratic process. Leaders in the schools in this study have made significant steps in the transformation of leadership, emphasizing participation. Despite the differences in approach and application, both participating schools were positive in their bid to shake off the shackles of bureaucracy. The next vital step to transformational leadership is the focal point of the research. 


\section{Transformational Collegial Leadership}

Specific interview questions were designed to elicit insight as to what extent leadership had transformed and how this had affected the development of human resources in the participating schools.

In What Ways Has Your School Shown a Vision for Future Leadership?

The question raised emphasized vision in schools. The way in which the vision was arrived at, its interpretation, its institutionalisation and the commitment shown by the members of the organization toward this vision, formed the basis of the questioning. Both participating schools acknowledged the importance of vision, but had different approaches to the formulation. Both participating schools also agreed that until the Schools Act of 1996, which stipulates that schools must have a vision, no real thought had gone into it. One teacher of Organization A noted:

Vision is just another term for planning and we have always planned at schools because our viewpoint has always been the one of failing to plan, is planning to fail.

This may be, but it is the process through which one goes when planning that determines whether or not the members of the organization will be committed to that plan. Charlton (1992) criticizes a 'master plan' that is designed by a select few and then imposed on people. Without the consultation of all stakeholders, people feel uninvolved and never feel ownership of such a document, which is consequently filed away only to be looked at the following year. Worse still, when the leaders of participating schools were asked what the vision or purpose of their organization was, they had to refer to the document itself rather than having internalized it. As the principal of Organization A said:

Our vision is a comprehensive document set up by a Doctor of Sociology in conjunction with staff members ... no I can't tell you what our vision is because it is very broad. ... It took about three weeks to set up.

Another teacher from the same school said:

I don't know what our vision is in a sentence because the whole document that was set up is part of our vision ... the document is difficult to understand.

The process of formulating the vision illustrates the difference between commitment and compliance. Short and Greer (1997) agree that a process, which includes as many stakeholders as possible and which is on-going, is more likely to be accepted by those affected and is more likely to bring about successful change. Telford (1996) emphasizes that only a clear, focused and common vision can hold an organization together and enable it to produce results. A further necessity regarding vision is that it is continually moving to embrace the rapid changes faced by the educational world. Leaders in Organization B were apparently enthusiastic when questioned about the vision of their school; their attitude toward the process and the vision was refreshing. The principal of the school initiated the process:

The directives came from the Department (of Education), but we were already in the planning stages. We meet every three months or once a term to review the school's vision and to check how much progress we have made towards our vision. ... Yes, it was a long process in formulating our vision; in fact we worked on it for a whole term ... teachers, parents and members of our community were involved and are still involved in the on-going process.

The principal of Organization B initiated the process. However, the vision did not originate from the principal, but from employees; and, in this sense, it is a shared vision. Charlton (1992) commends a leader that is guided by the people in the organization. Some characteristics that must guide the leader are:

- $\quad$ The dreams, aspirations and needs of the people.

- Why did they choose to work in that organization?

- What do they hope to achieve?

Copyright by author(s); CC-BY 
- What ideas do they have for organizational improvement?

- What do they want professionally?

What Has Your School Done to Institutionalize This Vision?

Ian McCrae, Eskom Chief Executive, (in Charlton, 1992) comments on the importance of listening to and staying in touch with the employees of the organization:

There is no better way to know how well or how badly things are going than to ask your staff and then to follow their advice. (p. 52)

This kind of leadership was apparent in Organization B where the principal relied on the staff and parents of the school in the formulation of the vision of the school.

Our vision, which realised different mission statements by the various groups, e.g. sport, cultural, academic and finance, is simple and clear and has been internalised by everyone in the school and is simply regarded by all stakeholders to be number one.

Not only was the vision clear and simple, but it also had already been internalized by teachers, parents, learners and members of the community. Wood (1984) also believes that values, structures and processes are necessary attributes in ensuring a commitment to mission and vision through empowerment, participation and trust. Teacher empowerment, according to Steyn and Squelch (1997), is very important in ensuring equitable participation and commitment to a school's vision. In this way, empowerment is rather an organizational dialogue in which there is a free exchange of knowledge and in which learning must occur so that everyone can contribute to the growth and development of the school.

How Has This Influenced the Employees?

A difference between Organization A and B is the way in which employees are empowered. Organization A leaders are of the assumption that participation is something which principals must give to teachers.

We Give Everybody a Chance to be a Leader and to Develop Professionally

Organization B, on the other hand, empowered teachers by involving them as leaders in their own areas of interest rather than as committee members to advise the principal, and also saw teachers as professionals who have a reservoir of knowledge, skills and talents that need to be tapped. One teacher at this school remarked:

Teachers are free to become involved where they feel they have something to contribute, there is no pressure of any sort on them to accept responsibilities they don't want.

This collegial leadership style allows employees to openly share goals and values that allow collaborative individualism (Charlton, 1992). Inherent in transformational leadership is the belief that leadership should not be limited to one individual or to those people holding administrative and supervisory positions. It should rather be shared in ways that encourage collegiality and commitment (Leonard \& Leonard, 1999). The findings clearly indicate that the use of collaborative leadership is the direction in which the two schools have moved to develop their human resources. This move toward TCL has demonstrated the following characteristics:

- $\quad$ Seek out and use individual skills and talents in the school

- $\quad$ Shared vision and the commitment of all stakeholders

- Institutionalisation of the vision

- Ownership of the vision

- Trust in each other

- $\quad$ The needs of individual accommodated

- A collegial cohesive staff functioning as a team

- A positive work environment toward improvement

Copyright by author(s); CC-BY 


\section{Comparative Analysis of Findings}

In the analysis of the literature and the investigation into the current practice of participating schools, it appears that in Organization A, an illusion of equal and democratic participation toward transformational leadership is created through the selective transfer of power to employees. It's evident that the traditional power holders in Organization A (principal, deputy head, heads of departments and senior teachers) continue to influence decisionmaking significantly. Therefore, the impression of a horizontal type of hierarchy, where power is evenly and equally shared, is a misleading one. This means that the lines of management in Organization A are still fixed in the traditional roles of bureaucracy and are, in essence, still of a supervisory nature rather than that of a facilitator. The motivation for this, according to Charlton (1992), is the current change in emphasis from task management to human resource management. The blame for the failure of education to reform rests, in a large measure, on existing power relationships in schools; relationships among teachers and administrators, parents and students (Leithwood, 1992). Although Organization A has made progress in the development of its leadership, the traditional powers have been reluctant and conservative in relinquishing and sharing their power. The following findings characterize their conservative approach to change:

- $\quad$ The maintenance of clear lines of authority

- $\quad$ The maintenance of the leadership team

- A hierarchical structure still prevalent

- $\quad$ Communication gap between management and staff and a lack of a shared vision

- Institutionalisation of vision not apparent

- $\quad$ Decision-making largely rests with management

- $\quad$ Teacher development not encouraged and power relationships still exist

These are some of the stumbling blocks which hamper transformational leadership development and prevent the school from making rapid strides in the achievement of its vision. In contrast, the employees of Organization B relied on a strong culture of participation where they emphasized participatory decision-making as far as possible. Also, they are based on a radically different form of power that is consensual and facilitative in nature - a form of power manifested through other people, not over other people. Such power arises in finding greater meaning in their work to meet higher level needs through their work and developing their TCL capabilities. This form of power is unlimited and has substantially enhanced the productivity of the school. Sarason (in Leithwood, 1992) explains that this kind of process makes people feel that they have a voice in matters that affect them and will take greater responsibility for what happens to the organization. Steyn and Squelch (1997) further reveal that this allows a natural adoption of a collegial approach that breaks down the barriers that keep teachers isolated from one another and enhances communication in contribution to decision-making, creating new norms and expectations for all employees.

Organization B was epitomized by sharing power, where power lies in the hands of many, and the school is characterized by an integrated approach to organizational structure. Ideas come from multiple sources and are combined into meaningful wholes. Patterns of leadership are transformational and focus on facilitating the shared vision of the school. Group tasks and responsibilities are directed toward innovation and experimentation, with improvement being a foremost expectation, centred on teams and workgroups which are formed according to need. Expertise and interest, rather than seniority or formal status, dictate the membership of each team or workgroup. The findings have proved how effective this has been for Organization B and can serve as a motivating force for other schools to follow their example. Therefore, the changed role of the principal in a transformational school culture is one of group facilitators, inspirational motivator, communicator, team builder, problem solver, information sharer, ideas promoter, conflict negotiator and, finally, the development of human resources (Telford, 1996).

\section{RECOMMENDATIONS}

\section{Shared Vision}

Management, in the traditional paradigm, is based on rules and regulations and the control of input and output. An innovative organizational paradigm to develop human resources is based on shared leadership and a Copyright by author(s); CC-BY 
shared vision. Visioning is dynamic and collegial, a process of articulating what the employees of an organization want to create together (Ancona, Malone, Orlikowski \& Senge, 2011). A deep awareness of the necessity for shared vision is the core of the new and the future paradigm in education (Uys, 1996). Many employees have a limited or tunnel vision because of their immediate jobs or roles and lack a clear perspective of the whole organization. The larger the organization, the more fragmented this perspective can be. When this occurs, employee contributions seem disjointed and the work of some may seem counterproductive to organizational effectiveness. Many employees may have gained promotion on technical skills and may be reluctant to abandon or modify skills and attitudes which have been valuable to them in the past (Elliot-Kemp \& Elliot-Kemp, 1992). Ancona et al. (2011) elucidate a vision's impact on organizational life as follows:

Even the most compelling vision will lose its power if it floats, unconnected, above the everyday reality of organizational life. To transform a vision of the future into a present-day reality, leaders need to devise processes that will give it life. This inventing is what moves a business from the abstract world of ideas to the concrete world of implementation. (p. 191)

A vision is also central to the transformational leader who has to get all the employees in the organization to move in the same direction. The commitment of all the human resources must be collegially acquired. The changes shown by Organization B can be described as a type of VAT (value added transformation) where the leaders of these organizations are in pursuit of fundamental goals which include helping staff members develop and maintain a collaborative, professional organizational culture; fostering human resource development, and helping employees solve problems together more effectively. As affirmed by Ancona et al., no "one person could possibly stay on top of everything, but the myth of the complete leader (and the attendant fear of appearing incompetent) makes many executives try to do just that, exhausting themselves and damaging their organizations in the process" (p. 180).

\section{Empowerment of Employees}

Empowerment is not the handing over of power to anyone who wants it; responsibilities and accountability that come with any sharing of power or direction will be lost and power relinquished (Singh, 2013b). Primary school leaders from a transformational perspective see everyone as a potential leader, with the focus being to enable others to act through fostering collaboration and strengthening others (Gibbon, 1995). This involves competencies, such as the effective use of power, developing others and the ability to cope, and initiating change from both the leader and the follower. The leader then becomes a catalyst for growth, through attention to structures, development opportunities for followers, and in the expectations and the manner in which interaction with people takes place (Charlton, 1992).

The two schools, however, did realize the importance of a harmonious, collegial working environment amongst employees that encourages communication and teamwork. Nevertheless, Van Wyk (1989) is of the opinion that the old adage of "leading a horse to water ..." applies here insofar as it is the principals of schools who can initiate and develop their employees' transformational leadership traits. The principals' role should be changed from the traditional bureaucratic view to one of shared vision and planning in the quest for obtaining and developing a successful team in their schools. Whitaker (1993) believes the TCL makes a fundamental power shift from the power of authority vested in a position, with power vested in the people. Power becomes spread among employees in the organization so that ownership can be felt by all of them. The redistribution of power in schools brings responsibilities to staff, parents and learners. According to Telford (1996), if the school culture is immersed in a belief in the democratic process, a valuing of the individual, a valuing of diversity and where interpersonal openness and caring and respect are the norm, school success can be won. The responsibilities that come with empowerment demand acceptance of and commitment to collegiality, such as taking a whole school focus, working with others in a democratic way to achieve a shared vision, valuing and respecting others' opinions, frequent communication, and sharing of information. These actions form an integral part of the transformational leadership process and, if taken from a principal's point of view, this will impact significantly on developing human resources in schools. follows:

George, Sims, McLean and Mayer (2011) succinctly describe the essence of empowering people to lead as 
Authentic leaders recognize that leadership is not about their success or about getting loyal subordinates to follow them. They know the key to a successful organization is having empowered leaders at all levels, including those who have no direct reports. They not only inspire those around them, they empower those individuals to step up and lead. (p. 176)

Superior results over a sustained period of time are the hallmarks of transformational leaders who espouse collegiality in creating maximum opportunities for all their employees.

\section{Nurturing Human Resources}

Although there was a commitment to change in the participating schools, it was clear that not all leaders knew how to implement this change or what TCL entailed. It is recommended that concrete steps be taken to train all leaders through seminars, academic courses and workshops to make them aware of what is involved in transformational leadership as opposed to TBMPs. The creation of negotiating procedures and structures, such as collegial transformation teams, would ensure a free flow of information which would encourage participation in the transformation of leadership styles. The rationale for the introduction of TCL would ensure that it creates the opportunity, supports the freedom, and develops the ability of all employees to be equally involved in the improvement of their organizations.

Teacher motivation for development is enhanced when they adopt a set of internalized goals for professional growth. This is further facilitated when they are involved in establishing a vision for the school to which they are strongly committed. Leaders can assist by ensuring that goals are clear, explicit and realistic. Leaders can also develop teachers by giving them problems related to school improvement within a collegial culture that values continuous professional growth. The leaders of democratic schools must be equipped with the knowledge, skills, abilities, beliefs, and dispositions that will allow them to succeed. The abilities should not only focus on cognition alone but also, equally, on the emotional intelligence of the leader (Singh, 2013a). Naturally, this would require that they become part of professional development and mentoring networks that would provide support whilst they serve in their capacity as educational leaders. It would also require a change in their educational preparation programmes and in the organizational structures in which they operate (Kochan \& Reed, 2005).

\section{Improving Group Problem-Solving}

Transformational leadership is valued because it stimulates employees to engage in new activities beyond the classroom and put in that extra effort which is so often lacking in the traditional school setting. The commitment of teachers in Organization B, where there was a culture of transformation, was clearly higher than that of Organization A, where teachers were not prepared to put in any extra effort. However, much of this extra effort can be utilised toward thinking smarter as well, rather than simply working harder only. Leaders of such schools assist group discussions, ensure open discussions and avoid commitment to preconceived solutions; they listen to different views and avoid biased perspectives. As was found on Organizsation B, the leaders also share a genuine belief that their employees could develop better solutions than the principal could do alone. Nasser and Vermeulen (1991) believe that management's responsibility is no longer command over people; it is responsible for contributing. The work of the transformational leader is the integration of human resources into a viable organism (teamwork). The rapid changes brought about by technology and other factors in the working environment urge educators to update their curriculum knowledge and leadership skills through continuous professional development such as further study, professional growth seminars and workshops.

All organizations are constantly in need of change. Transformation and change is about changing attitudes, perceptions, behaviours and expectations. Transformation should also be a process of growth. Transformational leadership should encompass a process of transformation. With any kind of change, however, there are stresses and strains that accompany it before growth can be achieved. O'Neill, Middlewood and Glover (1994) advocate an increased focus on employee contributions to organizational success. This entails a shift by education managers from traditional bureaucratic roles of leadership. Current realities and challenges place specific demands on the management of schools. Shrinking budgets, cuts in human and material resources, increasing demands on available personnel, insufficient parental support, and vague departmental policies and regulations strengthen the need for transformational leadership. 
The transformational approach must respond to needs amongst followers and must look for motives, extrinsic and intrinsic, to satisfy those needs by enhancing opportunities, empowering people and giving more freedom, performance evaluation, and the full support of the leader. This principal also needs to receive a substantial commitment of time and energy from teachers in a drive to change attitudes of colleagues, parents and learners of the school community where previously there were low levels of achievement and commitment. The education system of past years has made it very difficult to change because of the comfort zone of bureaucratic structures. Principals, deputies, heads of departments, and even teachers, find it difficult to move from this comfort zone, even if it means improving education for the learners. This was clearly evident in Organization A. Getting staff members involved in collaborative goal setting and reducing teachers' isolation by creating time for joint planning will foster and develop collegial skills. The active communication of the school's vision, values and beliefs in day-to-day interpersonal contacts, and the sharing of power and responsibilities, will also add to a culture of transformation because it will enhance opportunities for leadership development of all employees, increase the personal autonomy of teachers, and support employees to maximize organizational outcomes.

Change in our society is a reality, so why is there such reluctance toward it? Change brings with it uncertainty about what must be done, anxiety about the ability to cope with the ever tightening economic situation, and difficulty in allocating time and limited resources to these problems. Along with this is a lack of expertise and knowledge of how to implement a transformational approach. The resistance to change results from two factors fear of the unknown and personal loss. It could be that people have security in now because they know what is happening and they feel in control. The problem is the tomorrow which holds the unknown and a fear of losing that security and control. As pointed out by Kotter (2011), one of the reasons some organizations have difficulty adjusting to rapid changes in their environments is that so many employees feel relatively powerless. From experience, they have learned that even if they correctly perceive important internal and external changes and then attempt to initiate appropriate actions, they would be vulnerable to someone higher up in the management hierarchy who does not like what they have implemented. In order to overcome this management hurdle, a clear sense of direction must be communicated by collegial leaders throughout their organizations so that lower-level employees can initiate actions without the same degree of vulnerability (Kotter, 2011).

\section{CONCLUSION}

In a happy, functional work environment characterized by collegiality, one could expect to find employees and a leadership team that share responsibilities and accountabilities through the development of a common purpose. In order for this kind of capacity building to be encouraged, the principal needs to develop the personal competencies of the staff and empower them to solve problems, create new opportunities and overcome barriers. Such an educational goal is likely to be achieved in a collegial environment that recognizes the needs and abilities of every individual. Making schools functional and effective, therefore, will take more than just individual effort. Development and transformation embrace the values of collaboration, confrontation, authenticity, trust, support and openness. The organizational culture that is bureaucratic and intolerant of conflict will find it difficult to embrace the true spirit of transformation and development. Bureaucratic controls, scepticism and lack of leadership commitment and expertise are major features in preventing redirection. A commitment to a shared vision and the institutionalisation of the vision will provide the necessary direction. The more that change characterizes the working environment, the more the leaders must motivate their employees to provide leadership as well. If this works, then it would reproduce leadership across the entire organization, with people occupying multiple leadership roles throughout the hierarchy. This can be highly valuable to develop human resources because coping with change in any organization demands initiatives from a multitude of people. This can only succeed when TCL forms the bedrock of the organization.

\section{AUTHOR INFORMATION}

Prakash Singh is a professor of education at the Nelson Mandela Metropolitan University in Port Elizabeth, South Africa. He is currently a rated researcher by the National Research Foundation in South Africa, and is a former Senior Research Fulbright scholar. Professor Singh is the author of Innovative Strategies to Develop Better Schools and co-author of Principal Leadership. He has also published widely in peer-reviewed journals, focusing on collegial leadership, traditional bureaucratic management practices, organizational effectiveness, emotional 
intelligence, tobephobia, and self-regulated learning. Professor Singh has presented numerous papers at international conferences. E-mail: Prakash.Singh@nmmu.ac.za

\section{REFERENCES}

1. Ancona, D., Malone, T. W., Orlikowski, W. J., \& Senge, P. M. (2011). In praise of the incomplete leaders. In On leadership: HBR'S 10 most reads. Boston, Massachusetts: Harvard Business Review Press.

2. $\quad$ Anderson, G. (1990). Fundamentals of educational research. London: Falmer.

3. Barth, S. R. (2006). Improving relationships within the organisation house. The Best of Educational Leadership 2005 - 2006, 29-33.

4. Bennis, W. G. (1994). On becoming a leader. Massachusetts: Perseus.

5. Bush, T. (1993). Exploring collegiality: Theory, process and structure in managing organisations. Milton Keynes: Open University.

6. Carl, A. E., \& Franken, M. J. (1996). Die skoolhoof as visionêre leier in 'n tydperk van Transformasie. Die Unie, 7, 106-110.

7. $\quad$ Carlson, B. (1995). Changing educational paradigms. Stimulus, 3(2), 6-7.

8. Chapman, J. (Ed.). (1990). School-based decision making and management. Bassingstoke: Falmer.

9. $\quad$ Charlton, G. (1992). Leadership - the human race. Ndabeni: Juta.

10. Dantley, M. E. (2005). Moral leadership: Shifting the management paradigm. In F.W. English (Ed.). The Sage handbook of educational leadership. London: Sage.

11. Day, C. (2000). Effective leadership and reflective practice. Educational Leadership, 1, 113-127.

12. Duigan, P. A. (1990). School-based decision-making and management. Retrospect and prospect. In J. Chapman (Ed.). School-based decision-making and management. Bassingstoke: Falmer.

13. Elliot-Kemp, J., \& Elliot-Kemp, N. (1992). Managing change and development in schools. Essex: Longman.

14. Estler, S. E. (1988). Decision-making. In N. J. Boyan (Ed.), Handbook of research on educational administration. New York: Longman.

15. Gardner, L., \& Stough, C. (2002). Examining the relationship between leadership and emotional intelligence in senior level managers. Leadership and Organisation Development Journal, 23, 68-78.

16. George, B., Sims, P., McLean, A. N., \& Mayer, D. (2011). Discovering your authentic leadership. In On leadership: HBR'S 10 most reads. Boston, Massachusetts: Harvard Business Review Press.

17. Gibbon, J. (1995). School leadership reflections. Stimulus, 3(1), 2.

18. Harford, T. (2011). The logic of life. London: Brown.

19. Harford, T. (2012). The undercover economist. London: Brown.

20. Hellriegel, D., Jackson, S. E., Slocum, J., Staude, G., Amos, T., Klopper, H. B., Louw, L., \& Oosthuizen, T. (2006). Management. Oxford: Cape Town.

21. King, M. M., \& Van der Berg, O. (1991). The politics of curriculum: structures and processes. Pietermaritzburg: Centaur.

22. Kochan, F. K., \& Reed, C. J. (2005). Collaborative leadership, community building, and democracy in public education. In W. E Fenwick (Ed.). The Sage handbook of educational leadership. London: Sage.

23. Kotter, J. P. (2011). What leaders really do. In On leadership: HBR'S 10 most reads. Boston, Massachusetts: Harvard Business Review Press.

24. Kouzes, J. M., \& Posner, B. Z. (1997). The leadership challenge. San Francisco: Jossey-Bass.

25. Leithwood, K. A. (1992). The move towards transformational leadership. Educational Leadership, 49(5), 8-12.

26. Leonard, L. J., \& Leonard, P. E. (1999). Reculturing for collaboration and leadership. The Journal of Educational Research, 92(4), 237-242.

27. Nasser, M., \& Vermeulen, J. (1991). Shifting the focus from capital resources to human resources. Human Resource Management, 7, 26-28.

28. National Department of Education. (1998). Curriculum 2005. Pretoria: Government Publishers.

29. O'Neill, J., Middlewood, D., \& Glover, G. (1994). Managing human resources in schools and colleges. Essex: Longman.

30. Preedy, M. (1993). Managing the effective school. Milton Keynes: Open University. 
31. Roussouw, J. P. (1996). Veranderingsbestuur in skole, met verwysing na die skoolhoof as vernuwer. Die Unie, 92, 97-100.

32. Scheurich, J. J. (1997). Research method in the postmodern. London: Falmer.

33. Scott, D., \& Usher, R.(Eds.). (1996). Understanding educational research. London: Routledge.

34. Sergiovanni, T. J. (1991). The leadership: A reflective practice perspective. Boston: Allyn and Bacon.

35. Sergiovanni, T. J., Burlingame, M., Coombe, F. S., \& Thurston, P. W. (1992). Educational governance and administration. Englewood Cliffs: Prentice-Hall.

36. Short, P. M., \& Greer, J. T. (1997). Leadership in empowered schools. New Jersey: Merrill.

37. Singh, P. (2005). Use of the collegial leadership model of emancipation to transform traditional management practices in secondary schools. South African Journal of Education, 25, 11-18.

38. Singh, P. (2010). Innovative strategies to develop better schools. Sydney, Australia: Common Ground.

39. Singh, P. (2013a). A collegial approach in understanding leadership as a social skill. International Business and Economics Research Journal, 12(5), 489-502.

40. Singh, P. (2013b). Influence of the leaders' emotionally intelligent behaviours on their employees' job satisfaction. International Business \& Economics Research Journal, 12(7), 799-814.

41. Singh, P. (2013c). Transforming traditional bureaucratic management practices by employing the Collegial Leadership Model of Emancipation. International Business and Economics Research Journal, 12(8), 953968.

42. Singh, P. (2013d). Influence of leaders' intrapersonal competencies on employee job satisfaction. International Business and Economics Research Journal, 12(10), 1289-1302.

43. Stein, S. J., \& Book, H. E. (2001). The EQ edge: Emotional intelligence and your success. New York: Stoddart.

44. Steyn, G. M., \& Squelch, J. (1997). Exploring the perceptions of teacher empowerment in South Africa. A small-scale study. South African Journal of Education, 17(1), 1-6.

45. Telford, H. (1996). Transforming schools through collaborative leadership. London: Falmer.

46. Thilo, J. L. (2004). Emotional intelligence and leadership in the ASC. American Association of Ambulatory Surgery Centers. Retrieved from http://www.aaasc.org/features/monitor2003/FEA_030903_EmotionalIntelligenceLeadership.html

47. Uys, J. S. (1996). Aanspassings by 'n veranderde omgewing. Die Unie, 93, 31-35.

48. Van Wyk, C. (1989). The human resource practitioner's changing role. IPB Journal, 7, 10-14.

49. Veugelers, W., \& Zijlstra, H. (2002). What goes on in a network? Some Dutch experiences. International Journal of Leadership in Education, 5(2), 175-186.

50. West-Burnham, J., Bush, T., O'Neill, F., \& Glover, D. (1995). Leadership and strategic management. London: Pitman.

51. Whitaker, P. (1993). Managing change in schools. Philadelphia: Open University Press.

52. Wood, C. J. (1984). Participatory schools through collaborative leadership. London: Falmer. 


\section{NOTES}

